\title{
GROUND BASED AUGMENTATION SYSTEM (GBAS)
}

\author{
Salih BAŞAK \\ Commercial Pilot, Aircraft Maintenance Engineer, Turkish Airlines. \\ sbasak@thy.com \\ https://orcid.org/0000-0002-6887-9475 \\ Asst. Prof. Dr. Seçil ULUFER \\ İstanbul Aydın University, Anadolu Bil Vocational College \\ secilulufer@aydin.edu.tr \\ Prof. Dr. Muharrem YILMAZ \\ Kocaeli University, Faculty of Aeronautics and Astronautics, Dean. \\ myilmaz@kocaeli.edu.tr

\section{Assoc. Dr. Satılmış URGUN} \\ Kocaeli University Faculty of Aeronautics and Astronautics, Aircraft Electrical \\ and Electronics Department. \\ urgun@kocaeli.edu.tr

\section{Instructor Cahit BİLGi} \\ Aircraft Maintenance Engineer, Istanbul University, Vocational School of \\ Technical Sciences. \\ cahit.bilgi@istanbul.edu.tr
}

\begin{abstract}
The purpose of this article is to introduce the new technology of Ground Based Augmentation System by taking many factors into consideration such as, what this system is, the system equipment, its operating principle, installation costs, and advantages compared to other systems. Nowadays, many airports are not able to use their capacity adequately due to some disadvantages of approach systems, which is a serious cost for the enterprises. On the other hand, the fact that the number of equipment in the GBAS system is low and the transceiver signals
\end{abstract}


are not influenced by the air traffic around the system ensures the system to be more reliable and preferable in low visibility conditions while reducing the costs greatly.

Keywords: Ground Based Augmentation System, GPS, Precision Approach, GNSS, ILS, VOR

\section{YER BAZLI DESTEK SISTEMI}

\section{ÖZ}

Bu makalenin amacı, yer bazlı destek sisteminin ne olduğu, sistem ekipmanları, çalışma prensibi, kurulum maliyetleri, diğer sistemlere göre avantajları gibi birçok konuyu göz önünde bulundurarak yeni olan bu teknolojinin tanıtılmasını amaçlamaktadır. Günümüzde birçok havalimanı, işletmeler için ciddi bir maliyet olan yaklaşma sistemlerinin bazı dezavantajları nedeniyle kapasitelerini yeterince kullanamamaktadır. Öte yandan GBAS sistemindeki ekipman sayısının düşük olması ve alıcı-verici sinyallerinin sistem etrafındaki hava trafiğinden etkilenmemesi, sistemin daha düşük görüş şartlarında daha güvenilir ve tercih edilebilir olmasını sağlaması, maliyetleri büyük oranda düşürmektedir.

Anahtar Kelimeler: Yer Bazlı Destek Sistemi, GPS, Hassas yaklaşma, GNSS, ILS, VOR

\section{INTRODUCTION}

When we look at the history of aviation, we can see that the first flights could only be conducted according to visual flight rules, but with the development of technology over time and the increase of aviation requirements, instrument flights have begun to increase. Systems such as ILS, VOR, MLS, GPS, and GNSS have been constantly modernized and used to reduce the risk of incidents and accidents during approach and landing phases, which are crucial stages of the flight.

Sefer Ataş and his colleagues have advocated the use of satellite and ground assisted approach and landing systems that are less affected by environmental factors than the existing approach systems (ILS, MLS, PAR, VOR, DME, TACAN etc.) in their work (Ataş, 2015).

Along with the rapid increase in air traffic, the intensity of approach and landing has inevitably led to the development of more accurate systems, such as GBAS, which can provide multiple runways. 
Tim Murphy and his colleagues explored the use of the GBAS concept, architecture in comparison with the ILS in today's aviation industry. They emphasized the importance of understanding the use of GBAS use for air navigation clients, pilots and company managers, the accuracy of GBAS being much better than ILS, and that installation costs will be reduced (Murphy, 2008).

In addition, Mahbuba Ferdous and his colleagues have explained in the course of their work that two navigation systems can be used at the same time whether aircraft is on the auto mode or manual mode during approach and landing stages. ILS, MLS or GNSS assisted approach systems are not fed by a ground support system and so GPS errors can only be corrected by GBAS system. In their work, they found that all navigational nav-aids can provide CAT I conditions. On the other hand, ILS provides landing standards up to CAT III A, PDME and MLS provide landing standards up to CAT II and GPS-supported systems known as GBAS can provide CAT III B. CAT III C has not yet been used in the aviation (Ferdous, 2017).

Roberto Sabatini and his colleagues have argued that the integrated use of SBAS (Satellite Based Augmentation System) / GBAS (Ground Based Augmentation System) will provide more accurate flight information in the future. They also stated that these systems could be used on test flights of manned or unmanned aerial vehicles and can be used during an auto landing followed by a precise approach (Sabatini, 2017).

Dieter Guenter and Josep Dennis have reviewed the GBAS CAT I system at the Newark Liberty International Airport (EWR) and George Bush Intercontinental Airport (IAH) and expressed their satisfaction with using the system demanding that it should be upgraded to the GNSS-supported CAT III level (Guenter, 2015).

Apart from these studies, Per Schachtebeck and his colleagues did some investigations on the route with a real flight program, and also they experienced with the actual GBAS on the route and approach, researched the GBAS system installation on the Braun schweig station. With EUROCONTROL PEGASUS software, they were able to calculate the aircraft position with GBAS during an ongoing flight (Schachtebeck, 2006).

Jinsil Lee and his colleagues developed a real-time ionospheric threat modification method. They found that the reliability of GBAS was much higher than that of existing systems, arguing that the ionospheric effects could be corrected by $95 \%$ by analyzing the weather forecast data obtained between 1995 and 2011 (Lee, 2017). 


\section{GROUND BASED AUGMENTATION SYSTEM (GBAS)}

A Ground Based Augmentation System (GBAS) provides corrected position, path, and integrity data to the aircraft via VHF data broadcast. Two multi-mode receivers (MMRs) on board the aircraft translates the uplinked data that compute the airplane position and provides lateral and vertical path deviations. The goal of GBAS implementation is to provide an alternative to the Instrument Landing System (ILS). Current CAT I GBAS installations in the U. S. include EWR and IAH. GBAS Landing System (GLS) is the FAA's official term for a GBAS instrument approach procedure. The term GLS appears on the approach charts.

The Ground Based Augmentation system monitors and corrects the errors caused by the Global Navigation Satellite system (GNSS) and provides very precise navigation and approach data through VHF frequency and ground-based transmitters to all airports and runways located within $23 \mathrm{~nm}$ service. The GBAS system has a margin of error less than one meter in the horizontal and vertical path, providing very high accuracy and integration to the CAT I, especially for CAT II and CAT III precision approaches.

The FAA shares the data and experience gained in technical terms and operationally through the international GBAS working group (IGWG) with the countries and authorities in the GBAS working group. The last IGWG meeting with the participation of 16 countries took place in Everett, Washington by the Boeing Company. The organizations, airlines and countries involved in the meeting are; Air Services Australia, DECEA (Brazil), Deutsche Flugsicherung (Germany), AENA (Spain), Japan Civil Aviation Bureau, NATS (United Kingdom), DHMI (Turkey), Aerocivil (Colombia), Skyguide (Saudi Arabia), KARI (South Korea), Qantas, Japan Airlines, United Airlines and All Nippon Airways. Many participating countries and organizations have either started to use GBAS or have established prototypes or have participated in and are working in the work for technical and operational development. Sefer Atas and his friends think that GNSS-based approach and landing systems (GBAS) in later times would become very wide spread in the world and in Turkey, the to-do list certainly should have stated with the addition of GBAS (Ataş, 2014).

\section{GBAS FACILITIES}

A GBAS ground system typically has three or more GPS antennas, a central processing system (a computer), and a VHF Data Broadcast (VDB) transmitter locally located on or near an airport (Figure 1). The aircraft with GBAS has a GPS antenna, a very high frequency (VHF) antenna and related processing equipment. On airplanes, GBAS avionics multi-mode receiver (MMR) technology enables the implementation of GPS, GBAS and ILS at the same time using common 
antennas and equipment. GBAS ground equipment uses VHF radio connectivity of the aircrafts which have GPS corrections, integrity and approach phase information. The GBAS system with reference antennas is receiving signals from GPS satellites. The reference receivers measure the transmission time between the GPS satellite and the reference antenna and determine the distance the signal travels. The GBAS ground equipment then compares the actual distance based on the measured distance, the published satellite position and the actual GPS reference receiver position, and determines the error in the measurement. The average error measured by all operational reference receivers represents the correction term that GBAS avionics must apply to satellite ranges measured by GBAS avionics.

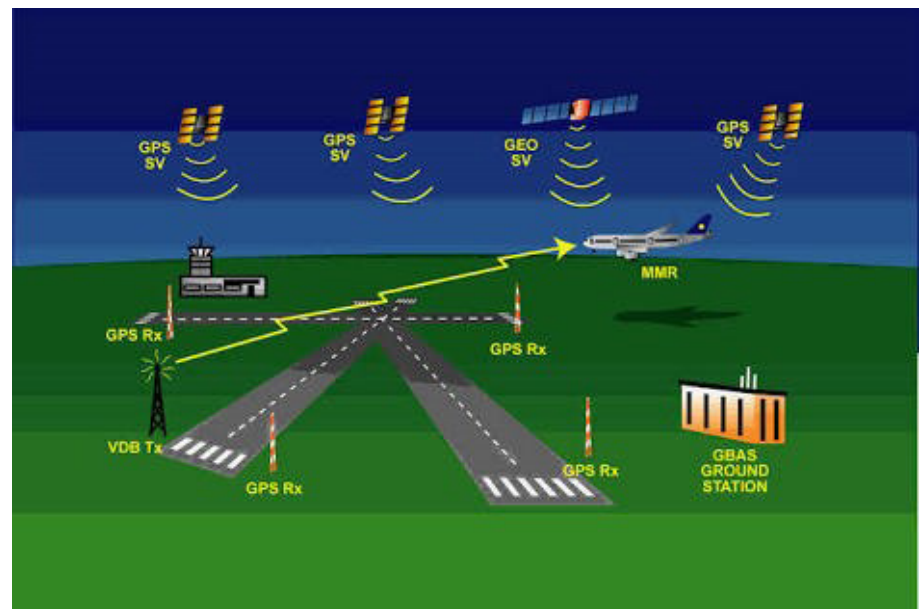

Figure 1: GBAS Equipments

The GBAS ground facility also monitors the overall GPS satellite performance. GBAS avionics use GPS satellites that only receive current ground corrections. When GBAS ground equipment determines that it is a potential problem with a GPS satellite or that it cannot track a GPS satellite, it stops the satellite corrections for that satellite and thus prevents GBAS avionics from using the satellite.

The GBAS ground equipment is the entire set of parameters, including the parameters that allow GBAS avionics to determine the limit at the calculated GPS position, and that only once in ten million calculations are incorrect, and that the calculated position is correct.

GBAS broadcasts a correction message twice updated every second through the VHF data broadcast (Figure 2). VDB messages provide guidance for approach by making corrections up to 48 accesses. 


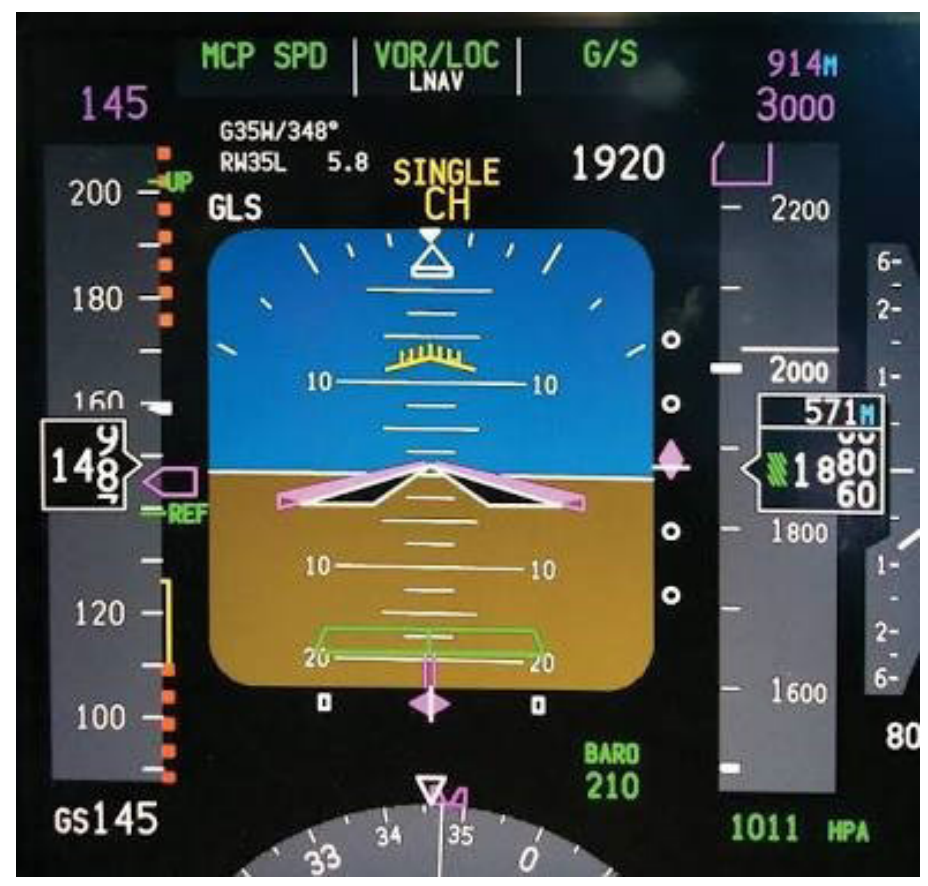

Figure 2: GBAS Ground Antenna

The VDB is broadcasting the GBAS signal in the GBAS coverage area to the avionics in the GBAS equipped aircraft (Figure 3).

GBAS servesits service in a local area (around $23 \mathrm{~nm}$ ). The GBAS service volume is designed to provide a precise approach and landing passage from the aircraft to and from the terminal airspace of the airport.

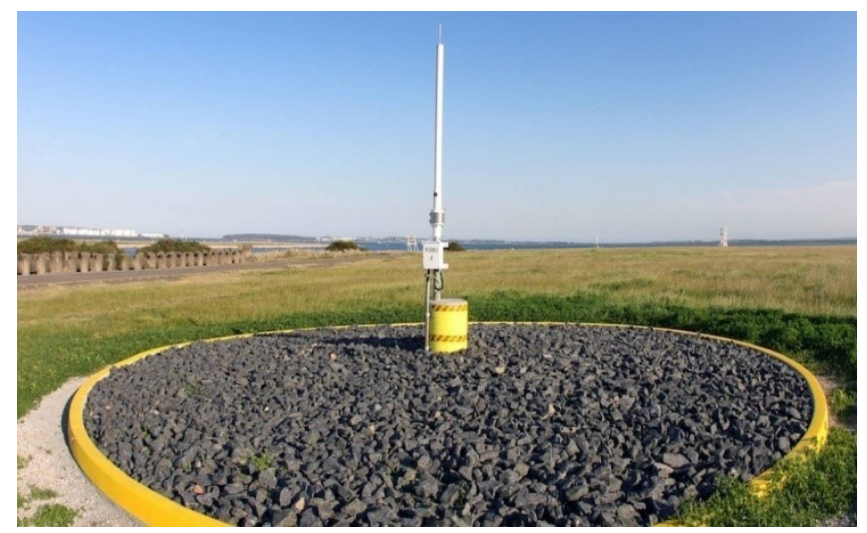

Figure 3: GBAS (GLS ) view on PFD 
The on-board GBAS equipment uses corrections to calculate the GPS position, speed, and time more accurately for aircraft to safely align the track. This signal provides guidance similar to that of the ILS. The current system has been approved for use at a minimum altitude value of 200 feet above the runway threshold by continuing research and development so that GBAS can be operationally approved to the track surface.

A Global Navigation Satellite System(GNSS), as defined by the International Civil Aviation Organization (ICAO), is a world wide location and time determination system that includes one or more satellite sets, aircraft receiver and system integrity monitoring. The navigation performance required for the operation is designed to meet the real-time integrity monitoring capabilities required by the existing satellite navigation systems (GPS, GLONASS), civil aviation navigation safety requirements. For example, if a satellite experiences a clock problem, there is no way for the GPS to warn the user quickly enough to avoid using that satellite. Fault sources, such as satellite or ionospheric delays can bring a few meters of error in the position of an aircraft. These faults should be corrected in real time for a sensitive approach. A number of augmentation systems have been installed to overcome the limitations above.

The ground-based augmentation system (GBAS) is primarily designed to support precision approach operations. It consists of a GBAS ground equipment system and a GBAS aircraft equipment system. A GBAS ground equipment system may support an unlimited number of aircraft units in the GBAS coverage area. The ground equipment system transmits approach phase data to aircraft and provides correction and integrity information for each satellite appearing. Corrections allow the aircraft to more accurately determine the position relative to the approach course. The GBAS signal in the recess is defined only as data that is broadcast locally to the aircraft subsystem. The satellite signals at the base are part of the basic GNSS satellite group.

The ground equipment infrastructure system for GBAS contains two or more GNSS receivers that collect information for the wrong GNSS satellites and compute and publish information on different fixes and integrity based on the compared (reference) location. These differential corrections are transmitted over the very high frequency (VHF) data broadcast (VDB) from the ground system. It includes various locally relevant data such as publication information, incorrect field corrections, integrity parameters and last approach phase (FAS) data referenced to the world geodetic system (WGS-84). Aircrafts within the coverage of the ground station may use broadcast corrections to calculate their own measurements in the direction of the differential principle. The different corrected position is used to generate navigation reference signals. 


\section{GBAS - ILS AND OTHER SYSTEM DIFFERENCES}

Today, ILS system, one of the preferred precision approach systems in many airports, needs to be specifically positioned for each runway. Despite the system's precise operation, the installation and maintenance costs reaching several million US dollars per year make it mandatory for the aviation industry to deploy and use systems such as GBAS, which can provide more than one runway service at a lower cost. These systems, which provide satellite based and very sensitive approach, are predicted to be indispensable landing systems for the future due to the many approach lines and the provision of service to the runway. As can be seen in Figure 4, the precise approach systems for the ILS and MLS are to be installed separately for each runway and the infrastructure must be prepared accordingly. For GBAS, only one ground system is available and it provides information to all the runways at the nearby airports where it is known.

In addition to these advantages of GBAS, it permits to establish on the landing course via final approach fix which means shortening distance and saving time. Especially, during non-precision approaches such as VOR and NDB, and at some airports for ILS approaches, when the full procedure has been applied on the approach plate, it causes to fly approximately $20 \mathrm{~nm}$ more to align with the final approach course, and this means more fuel will be burned. It is also unfortunately in the aviation records that a plane establishing on the landing path can be exposed to an accidental danger, affected by signal disturbances of the localizer and glide slope line of the ILS.

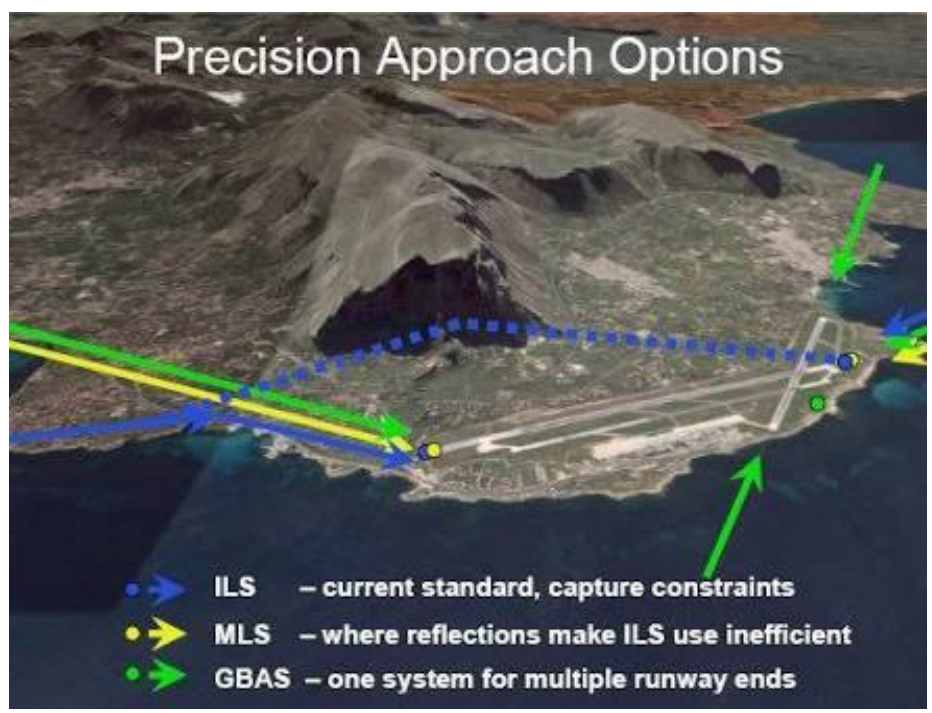

Figure 4: GBAS, MLS and ILS landingpaths 
Ground Based Augmentation System has lots of benefits. These are: increasing airport efficiency which enables flexible approaches, synergistic with RNAV/RNP transitions, lower airport maintenance costs since one GBAS serves all runways, lower acquisition and recurrent maintenance costs, accommodates growth to CAT II/III (expected in between 2018-2020), increases the level of safety by offering signal stability (no beam bending/FM frequency interference from preceding), approach procedures identical to single channel CAT I ILS procedures, lateral and vertical course guidance in reference to LOC and GS needles are identical, reduced noise/shorter routes with multiple glide-paths, displaced touch down points, and ofset paths enable reduced wake turbulence separation and lower noise levels over sensitive communities, lower approach minimums and future auto land capability.

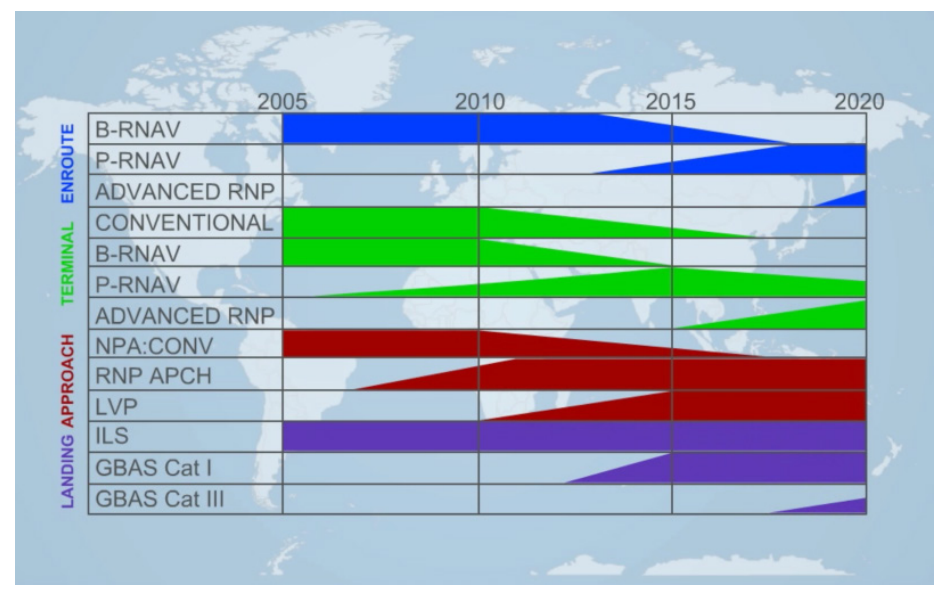

Figure 5: Approach and Landing System demands in time

When we compare the GBAS system to non-precision approach systems such as NDB and VOR, their differences are obvious, therefore their cost and reliability are much higher. Figure 5 shows the use rates of the approach systems over the years, along the route, as well as during the approach and landing phases. Despite the gradual decrease in demand for non-precision types of approach, it is also seen in the graph that satellite and ground based precision approaches and landing systems such as GBAS are more prefered.

\section{CONCLUSION}

There are many reasons for the establishment of the precision systems such as Ground Based Augmentation System (GBAS) at the airports which especially have geographical difficulties to make a precision approach. Nowadays, at some airports around the world we see that the GBAS CAT I approach system is in use and CAT III approach technology will be in progress in a short future. 
It is predicted that the system will be preferred by many aircraft operators in the future because the cost of GBAS is much less than the other systems, the ease of installation is less costly for aircraft operators. In the face of such a demand, the authorities will make more efforts to establish the GBAS system.

Due to geographical reasons, many aviation accidents have come to the fore in the past because of the incapable precise approach systems. In Turkey, the airports of the cities such as Van, Kahramanmaras, Igdir which are surrounded by mountains and a variety of terrains, the lack of a precise system such as GBAS has caused incidents and accidents in the past. Similar situations have occured both in Turkey and at the many airports of some different countries. Due to these reasons, we strongly recommend to the autorities such as DHMI in Turkey to build GBAS system in all the airports thoughout the country. In particular, if the GBAS system is installed in such airports the system ensures safe flights despite low visibility and limited space around airport.

There are very few factors that degrade the signals of the GBAS system compared to other systems. It is accepted that when the GPS signals are passed through the ionosphere and the equipment calibration errors, the sensitivity of the system is close to one hundred percent. From time to time, the GBAS system, which gives a deflection error of only a few centimeters, will take its place in aviation technology of the future.

In future work with GBAS, we recommend researchers to investigate issues such as how the system behaves in case of any equipment failure, whether a backup system is required, and how much deviation is caused by the aircraft in the event of a malfunction.

\section{REFERENCES}

Ataş, Sefer, et al. "GNSS based augmentation systems aviation perspective and vision for Turkey." Recent Advances in Space Technologies (RAST), 2015 7th International Conference on. IEEE, 2015.

Murphy, Tim, and Thomas Imrich. "Implementation and operational use of Ground-Based Augmentation Systems (GBASs) - A component of the future air traffic management system." Proceedings of the IEEE 96.12 (2008): 1936-1957.

Ferdous, Mahbuba, et al. "Comparative study of aircraft approach and landing performance using ILS, MLS and GLS.” AIP Conference Proceedings. Vol. 1919. No. 1. AIP Publishing, 2017. 
Sabatini, Roberto, Terry Moore, and Subramanian Ramasamy. "Global navigation satellite systems performance analysis and augmentations trategies in aviation." Progress in Aerospace Sciences (2017).

Guenter, Dieter, and Joseph Dennis. "Initial operational experience with CAT I ground based augmentation system (GBAS)." Integrated Communication, Navigation, and Surveillance Conference (ICNS), 2015. IEEE, 2015.

Schachtebeck, Per, Thomas Feuerle, and Peter Hecker. "Flight Testing and Data Evaluation of Ground-Based Augmentation Systems." 25th Digital Avionics Systems Conference, 2006 IEEE/AIAA. IEEE, 2006.

Lee, Jinsil, et al. "Real-Time Ionospheric Threat Adaptation Using a Space Weather Prediction for GNSS-Based Aircraft Landing Systems." IEEE Transactions on Intelligent Transportation Systems 18.7 (2017): 1752-1761.

Ataş, Sefer, et al. "YAKLAŞMA INIŞ SISTEMLERINDE ILERI

TEKNOLOJILER. ” Journal of Aeronautics and Space Technologies (Havacilik ve Uzay Teknolojileri Dergisi) 2.7 (2014): 1-12.

http://instrument.landingsystem.com/

http://www.ctatca.org/pdfs/ILS.pdf

http://www.dtic.mil/dtic/tr/fulltext/u2/a138301.pdf

https://fenix.tecnico.ulisboa.pt/downloadFile/395137480875/dissertacao.pdf

https://www.slideshare.net/mobile/JoanErencia/master-thesis-final-presentation http://www.eurocontrol.int/gbas 